\title{
Research on Factors Influencing Students' Reading Ability at Medical College
}

\author{
Sun Xiuping \\ Chuxiong Medical College, Yunnan Chuxiong, 675005
}

Keywords: influencing factor; reading ability; reading strategy; English learning

\begin{abstract}
Reading plays an important role in English learning, especially in the examination of PET and the exam of students upgrading from high school to university. This study has focused on finding out factors that influence students' reading ability in English teaching and learning at Chuxiong Medical College. And at the same time the researcher suggested that facilitate the reading strategies to develop the students' reading ability in accordance with the different factors. This study may also develop the space for its application and arouse greater interest in its research.
\end{abstract}

\section{Factors Influencing Students’ Reading Ability}

The cultural background of a passage is one of the main factors that influence students' reading comprehension. It involves understanding what authors tone, taking many aspects of the content and background knowledge into consideration. Sometimes understanding the cultural background is far more important than understanding what words and sentences mean. E.g. "The United States has gone from Peanuts to Popcorns, when Ronald Regan became President for the first time." If students do not know the background, they cannot understand the sentence though they know the meaning of the sentence. Former President Jimmy Carter owned a big peanut farm while Ronald Regan was an actor and people eat popcorns while watching TV. If students know about this, they will begin to appreciate the humor. For example, before reading the passage Good Manners, it is very helpful for students to learn the cultural background about the customs and manners of the native speakers.

\subsection{Greeting}

The simplest thing to say when greeting someone in English is "Good morning /afternoon/evening," depending on when you meet him/her. This greeting may be given to someone not very familiar or to someone you are passing quickly. "How are you?" is usually used when you are not in hurry. No answer is expected other than "Fine, thank you." "Hello" is the commonest form of greeting between good friends. To greet a total stranger, one usually says "How do you do?"

\subsection{Topics to Avoid}

In the west, there are certain things which are considered not suitable to talk about in public. The subjects to be avoided are as follows: bodily functions or anything connected with the private parts of the body, details of birth, details of unpleasant illnesses, income or salary, prices of one's possessions, the age of the person one is talking with, personal questions or remarks such as "Why don't you get married?" or "I think you would want to have children." Some of these topics are allowed in Chinese culture, but they are all taboos in the West. If students know something about this cultural background, they will understand the passage fluently.

It is important to note that vocabulary is not only important for learners to read but also for the development of verbal intelligence. Because every passage has some new words and phrases, so it is important to organize words around core concepts. When words are categories by common threads and linked to overarching structure of a passage, students see how the terms fit together to form a big picture. In addition, by slotting specific words into a comprehensive framework, the problem of information overload is greatly reduced. For example:

Ecology: 
1) How are essential substances replenished?
a. Water cycle
b. carbon cycle
c. nitrogen cycle

2) What is an ecosystem?
a. All living things' habitat
b. population habitat niche

3) What is Ecocity?

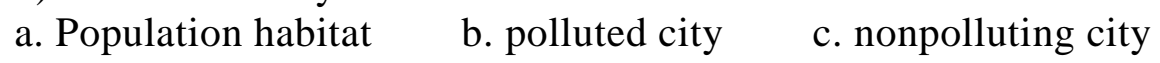

4) what's so great about an Ecocity?

a. Use of renewable resources b. balance with nature and other livings

5) How do changes in communities occur?

a. Pioneer community climax community b. primary succession secondary succession

A constructivist twist on vocabulary organization asks students to organize words into meaningful categories on their own or in groups. This classification technique, based on a learning model developed by Hilda Tabe (1971), helps students construct a personally resonant image of a passage structure and make predictions about content based on key vocabulary. (vocabularies need to be a mix of familiar and unfamiliar words so students can create categories using their prior knowledge.)

All the time vocabulary is regarded as one of the chief factors which influence students' reading. Really it is the case. Lack of vocabulary will not only directly obstruct students' reading comprehension, but also prevent them from going on, and will slow down their reading speed. If they do not know two or three crucial nouns or verbs in the opening sentences, students will quite probably give up reading. As Greenwood says (1981,cited in Stern, P89) "reading comprehension will include tackling problems of lexical difficulty." When dealing with reading materials with more new words, teachers should decide on some of the new key words that influence students' comprehending of the passage and present them at an appropriate time, in explicit ways before reading. Moreover, the new vocabulary should be controlled within 3\% of the total words of the given passage according to the New Standard. But teachers should not forget that students might be able to work out the structure of a passage and to transfer information into another form, although they have difficulties with certain words. The World Knowledge

The factor that should be emphasized is the world knowledge, which is often neglected by both teachers and students. The range of the world knowledge includes specialized knowledge in different fields such as finance, business, traveling, etc., universal experienced phenomena like failure and success and the common sense of daily life, e.g. rain is wet, snow is white or guns can kill. All these contain typical vocabulary and structures. If they know the background of a given passage, but they do not know the world knowledge about the passage, the result will be the same as the other factors that can obstruct students reading and comprehending it. Because of this, a teacher should consider this factor and prepare the relevant world knowledge for students when he designs activities for reading lessons. For instance, when the topic of traveling is concerned and they have known much of the world knowledge about traveling, students will anticipate where to go, when to leave, what kinds of vehicles to take, etc. Of course, they can figure out many of the typical words about traveling which they have not yet learned. E.g. a travel brochure is a small book from which you can get detailed information about traveling and a motel is a place where you can stay for the night and park your car. These words are not difficult for students to guess if they are in the contexts. Other unknown words are also easy to figure out though they are not in the contexts such as sleeping bag, guide, back-pack and so on. It is because of the world knowledge that students have known about traveling. Therefore, teachers should motivate students to use their world knowledge in solving reading problems so that they can learn more new words quickly and understand the passage better. Most important all, the modern society is an information era, teachers can teach the students search a lot of world knowledge we want to know on Internet. At Chuxiong Medical College, according to the questionnaire, a third of students can not search information about world knowledge on Internet. The researcher suggests that teachers should make use of network resources on Internet and teach students to learn how to search English knowledge on Internet. 
It is important to keep in mind that reading is not an invariant skill, and the way you tackle the tasks is strongly influenced by your purpose. There are several types of reading strategies that correspond to many different purposes that readers have for reading. The first type is skimming, focusing on the main idea, general understanding, timed reading through the passage to recognize the main point. The second one is scanning, glancing through a text to locate specific information (e.g. a name, data, date, etc.) There are also other types of reading such as predicting, skipping, clustering, close reading and guessing words from contexts and so on. These kinds of reading strategies are also important. In short, while reading, readers should read different types of passages by using different strategies.

Active promotion of reading is needed if teachers want good results. Reading habits are one of the main factors influencing students' reading comprehension. It is difficult for the students to establish the reading habit. The researcher searches for promoting the reading habit is that increase the number of reading assignments gives one prong of a two-pronged approach to increasing the amount of reading done. The second is to make students want to read. Needing to read, for study or other purposes, is an incentive for some students, but wanting to read is an incentive for all the students. Reading habits can improve reading comprehension ability and reading speed. In the experimental class, some students respond slowly or not at all to the attractions of reading, but many more develop a real appetite for it. Where reading is actively promoted, and plenty of enjoyable reading materials should be available. But to provide enough reading materials for the students is the most important and difficult thing at Chuxiong Medical College. A great deal depends on reading a lot of reading materials to become an effective reader, and it is far more useful to read a lot of easy reading materials than a few difficult ones. In this way, The College Library should have at least twice as many English books or reading materials as there are students. In fact most of books or materials are in the field of medicine and health science. So to deal with the English reading materials or books is a big problem at present.

During the reading processes, there are many factors that will influence students' reading comprehension. Apart from the main factors mentioned above, there are also other important factors that obstruct students comprehending the reading materials. These factors include traditional reading methods in the atmosphere of the traditional English teaching, students' motivation, etc, which should not be neglected in teaching of reading. Teachers should focus great emphasis on training students' reading strategies. In the meantime, teachers should pay much attention to students' interest and new strategy training, and try to avoid disadvantages in reading teaching. As a teacher, he or she should manage to help students overcome these problems.

\section{Strategies to Facilitate the Reading}

Part-centered ( also called Code-emphasis or Bottom-up ) strategy, which views reading instruction as moving from learning the "parts" and building up to the "whole". In bottom-up processing, the readers build up a meaning from the black marks on the page: recognizing letters and words, working out sentence structure. They can make conscious use of it when an initial reading leaves them confused. For example, sometimes if readers can not believe that the apparent message was really what the writer intended; this can happen if their world knowledge is inadequate, or if the writer's point of view is very different from their own. In that case, the readers must scrutinize the vocabulary and syntax to make sure they have grasped the plain sense correctly. Thus bottom-up processing can be used as a corrective to 'tunnel vision' (seeing things only form readers' limited point of view).

Socio-psycholinguistic (also called Meaning-emphasis or Top-down) strategy, which emphasize the overall construction of meaning from connected or whole texts, and draw on the reader's and writer's schemata and personal experiences. This kind of strategy processing is used when readers interpret assumptions and draw inferences. The readers make conscious use of it when they try to see the overall purpose of the passage, or get a rough idea of the pattern of 
the writer's argument, in order to make a reasoned guess at the passage step. This enables readers to predict the writer's purpose, the likely trend of the argument and so on, and then use third framework to interpret difficult parts of the passage. The top-down strategy gives a sense of perspective and makes use of all that the readers bring to the passage: prior knowledge, common sense, etc, which have sometimes been under valued in the reading class.

That is to say the readers simply let their eyes wander over the passage until they find what they are looking for, whether it be a name, a date, or a less specific piece of information.

When readers use skimming strategy, first they should know predicting is the core of skimming. It is the faculty of predicting or guessing what is to come next and making use of grammatical, logical and cultural clues. Unlike predicting, previewing is the core of scanning which involves using the table of contents, the appendix, the preface, the chapter and paragraph headings in order to find out where the required information is likely to be.

The key to skimming is to find the main idea of the selection or different paragraphs, and to be able to synthesize them into an organic whole by way of generalization. Skimming involves reading as quickly as possible to get the gist of a text or part of a text. Students should focus on reading the title, considering the format, and glancing relatively quickly through the text, looking most closely at the topic sentence of each paragraph to determine the researcher's view point. Scanning, on the contrary, is far more limited since it only means retrieving what information is relevant to readers' purpose. Yet it is usual to make use of these two strategies together when reading a given passage. For instance, readers may well skim through an article first just to know whether it is worth reading. Then read it through more carefully because they have decided that it is interesting. It is also possible afterwards to scan the same article in order to note down a figure or a name which they particularly want to remember.

Summarizing which is an essential reading comprehension strategy because it involves selecting what most important from a reading passage and committing that to memory stage. Summarizing can be compared with managing computer files; we say what we need for our work, and we recycle what we do not need. Recalling information from a reading passage can result in overloading or no retenting of the reading material. With summarizing, the most important details as well as the main ideas are identified. The following four rules are helpful for teaching students to produce summaries. 1) identify the main ideas, 2) detrivial information, 3) delete redundant information, and 4) relate the ideas and supporting information. (Nunan, 1995, P.86)

Have students summarize after reading progressively longer materials. First, have them summarize a paragraph, then two paragraphs, then a section then a chapter, and then a book. Gradually increase the amount of inform included in the summary. Initially, have students write a one-sentence summary, then a paragraph with the topic sentence stating the main idea, and the body of the paragraph giving the important details. For longer materials have the students write the summary in outline form so that they can subordinate all the major ideas and the subordinate ideas under each. They can also information on cards and do word sorts in which they match details with responding main ideas. Students can create graphic organizers to repeat major and subordinate ideas.

The finding shows that reading strategy training can facilitate the teaching of reading, and it is definitely effective to the low and high achievers. Moreover, the low achievers got much beneficial from reading strategy training in PET than that of high achievers. But a few were at a loss what to do when they were trained for using reading strategies while learning.

\section{Conclusion}

Finding out the factors that influence the students' reading ability and then facilitate reading strategy training have positive effects on teaching of reading mainly because it can improve the students' reading speed, reading accuracy and increase their self-confidence, arouse their interest in reading and so get learners inclined. Generally speaking, reading strategy training is positively helpful to get a good result in PET and motivate the students to learn English at Chuxiong Medical 
College. The fact is that reading strategy training can facilitate the teaching of reading, and it is definitely effective to the English learners. Moreover, the learners are much beneficial from reading strategy training in PET.

\section{References}

[1] Baltimore, Esther Minskoff Ph.D.(2002). Teaching reading for struggling learners. [M] U.S.A.

[2] Block, E.L. (1986). The comprehension strategies of second language readers. [J] TESOL Quart erly, 20, 463-464.

[3] Cairney, T. H. (1990). Teaching reading comprehension. [M] Open University Press. 